\title{
Expression of bacteriocin divercin AS7 in Escherichia coli and its functional analysis
}

\author{
Agnieszka K. Olejnik-Schmidt • Marcin T. Schmidt • \\ Anna Sip • Tomasz Szablewski • Wlodzimierz Grajek
}

Received: 2 April 2013 / Accepted: 29 October 2013 / Published online: 27 November 2013

(C) The Author(s) 2013. This article is published with open access at Springerlink.com

\begin{abstract}
Bacteriocins are small peptides with antimicrobial activity, that are produced by bacteria. Four classes of bacteriocins produced by lactic acid bacteria have been defined. Class IIa bacteriocins are promising candidates for industrial applications due to their high biological activity and their physicochemical properties. Divercin AS7 is a class IIa bacteriocin produced by Carnobacterium divergens AS7. It shows antibacterial activity against pathogens and food spoilage flora including Listeria spp. Little is known about the impact of class IIa bacteriocins upon eukaryotic cells. The safe use of bacteriocins as food biopreservatives requires the absence of cytotoxicity to human cells. To analyze the impact of divercin AS7 on human enterocytes, we expressed the recombinant divercin AS7 in the Escherichia coli BL21DE3pLys strain and conducted in vitro studies to evaluate the safety of recombinant divercin AS7. No cytotoxic effect on differentiated monolayer Caco-2 cells and no apoptotic appearance were observed when recombinant divercin AS7 was used at a concentration of $2 \mu \mathrm{g} \mathrm{ml}^{-1}$. In our study, divercin AS7 also did not interfere with differentiated Caco-2 cells monolayer integrity. The obtained results suggest that divercin AS7 is a promising peptide for the food industry.
\end{abstract}

Keywords Bacteriocins $\cdot$ Divercin AS7 $\cdot$ Human enterocytes $\cdot$ Biopreservatives

\footnotetext{
A. K. Olejnik-Schmidt $(\triangle) \cdot$ M. T. Schmidt $\cdot$ A. Sip $\cdot$ W. Grajek Department of Biotechnology and Food Microbiology, Poznan University of Life Sciences,

Wojska Polskiego Street No. 48, 60-627 Poznań, Poland

e-mail: agao@up.poznan.pl

T. Szablewski

Department of Food Quality Management, Poznan University of Life Sciences, Wojska Polskiego Street No. 31, 60-624 Poznań, Poland
}

\section{Introduction}

Bacteriocins are a heterogenous group of anti-bacterial ribosomally synthesized peptides. Lactic acid bacteria (LAB) produce bacteriocins that vary in their spectrum of activity and biochemical properties (Abee et al. 1995). Four classes of $\mathrm{LAB}$ bacteriocins have been defined on the basis of their structural characteristics. Class IIa bacteriocins are cationic heat-stable and membrane-active peptides containing disulfide bonds (Klaenhammer 1993; Nes et al. 1996). Bacteriocins could be useful as natural and non-toxic food preservatives. They can be produced in situ by bacteriocinogenic cultures or introduced to foods as additives (Abee et al. 1995). Moreover, some of them could be considered for other applications in human health (Todorov et al. 2010), and may also provide new approaches to combat antibiotic-resistant bacteria (Parisien et al. 2008). Divercin AS7 is a class IIa bacteriocin produced by Carnobacterium divergens AS7, a lactic acid bacterium isolated from fish. The amino acid sequence of divercin AS7 showed high homologies with divercin V41 and pediocin PA1. These bacteriocins contain two disulfide bonds responsible for their wider activity spectrum (Metivier et al. 1998). As its homologs, divercin AS7 shows antagonistic activity against closely related species, e.g., Carnobacterium piscicola (Sip et al. 1998) as well as foodborne pathogens, especially Listeria spp. (Lebois et al. 2004; Richard et al. 2003). Therefore, many studies are currently conducted to test the usefulness of divercin AS7 as a food or a feed additive (Jozefiak et al. 2011). Information is limited on the impact of class IIa bacteriocins upon eukaryotic cells, especially human enterocytes. To evaluate the safety of this kind of biopreservative, the cytotoxicity of purified bacteriocins should be determined. Studies on nisin used as food additive no. E234 (Directive 96/77/EC) shows contradictory data (Maher and McClean 2006; Murinda et al. 2003). It seems that the impact of nisin on humans cells is dependent 
on the type of cell and the amount of bacteriocin used in the test. Production of divercin AS7 by Carnobacterium diverges AS7 is very effective and optimized (Sip et al. 1998). The purification of this bacteriocin, as for other class IIa bacteriocins, is time-consuming and involves critical steps (Berjeaud and Cenatiempo 2004).

We used a heterologous expression system (Escherichia coli) to obtain bacteriocin divercin AS7 containing histidinetag (His-Tag), purified recombinant protein and analyzed its impact on human intestinal cells Caco-2. This cell line is one of the in vitro systems most often used to mimic human intestine, and has the capacity to differentiate and express brush border enzymes (Di Cagno et al. 2010). These cells under culture conditions develop the morphological and functional characteristics of mature enterocytes. As far as we know, the presented work is the first to focus on the expression of a native gene encoding divercin AS7 to obtain a tagged protein in the E. coli heterologous system, and to test its functionality on human cells.

\section{Materials and methods}

\section{Bacterial strains and media}

Escherichia coli strain JM109 (Stratagene) was used for standard cloning procedures, and E. coli strain BL21(DE3)(pLysS) (Novagen) was used for gene expression experiments. Escherichia coli strains were grown aerobically in Luria-Bertani (LB) or SOC medium at $37^{\circ} \mathrm{C}$. Chemically competent cells and transformation of $E$. coli were prepared using standard procedures (Sambrook et al. 1989). The plasmid pET-28b + (Novagen) was used for gene construction and expression. Transformants harboring pET28b + were selected on LB agar medium containing $25 \mu \mathrm{g} \mathrm{ml}^{-1}$ kanamycin (for E. coli JM109) and LB agar medium containing $25 \mu \mathrm{g} \mathrm{ml}^{-1}$ kanamycin and $30 \mu \mathrm{g} \mathrm{ml}^{-1}$ chloramphenicol (for E. coli BL21DE3pLysS). Carnobacterium divergens AS7, a native divercin AS7 producer, was grown in MRS medium without Tween 80 at $30{ }^{\circ} \mathrm{C}$ and without shaking (De Man et al. 1960). Listeria innocua (ATCC33090), used as a divercin AS7-sensitive indicator microorganism, was grown in $\mathrm{LZ}$ medium at $37^{\circ} \mathrm{C}$ without shaking.

Recombinant plasmid construction

PCR primers used for this study were designed on the basis of DNA sequence for divercin V41 (AJ224003, GeneBank) and restriction enzymes sites for $E c o$ RI and NotI were introduced into forward (5'-ATCAAGAATTCAACAAAATATTATGG GAAT- $3^{\prime}$ ) and reverse (5'-ATTTTTGCGGCCGCTTAGCA TTTACCTGGTA-3') oligonucleotides, respectively. The oligonucleotides were purchased from the Institute of
Biochemistry and Biophysics, Polish Academy of Sciences. The chromosomal DNA of $C$. divergens AS7 was used as a template in PCR amplification. The PCR reaction was conducted using 35 cycles of denaturing at $95{ }^{\circ} \mathrm{C}$ for $30 \mathrm{~s}$, annealing at $54{ }^{\circ} \mathrm{C}$ for $30 \mathrm{~s}$, and elongation at $72{ }^{\circ} \mathrm{C}$ for 1 min with BiometraT Gradient Thermal cycler. The amplicon was digested with $E c o$ RI and Not I enzymes (Fermentas). The digested PCR fragment and linearyzed pET28b+ vector were purified from agarose gel using Gel-OUT Kit (A\&A Biotechnology) according to the manufacturer's recommendations. ORF AS7 was ligated into pET28b+ using T4 DNA ligase (Promega). Recombinant plasmid pET-AS7 was purified using Plasmid Mini Kit (A\&A Biotechnology). The nucleotide sequence of the cloned DNA was analyzed using automated sequencing at the Institute of Biochemistry and Biophysics, Polish Academy of Sciences. The recombinant plasmid were verified by double digestion with Eco RI and Not I.

Expression of divercin AS7 in E. coli

Overnight culture of $E$. coli strain BL21DE3pLysS harboring the recombinant plasmid pET-AS7 was diluted to $3 \%(\mathrm{v} / \mathrm{v})$ in SOC medium containing kanamycin $\left(25 \mu \mathrm{g} \mathrm{ml}^{-1}\right)$ and chloramphenicol $\left(30 \mu \mathrm{g} \mathrm{ml}^{-1}\right)$, and grown aerobically at $37^{\circ} \mathrm{C}$ until the culture reached a density of 0.6 at $600 \mathrm{~nm}$ (measured in a spectrophotometer). Induction of gene expression was done by the addition of isopropyl- $\beta$-D-thiogalactopyranoside (IPTG) to a final concentration of $0.1 \mathrm{mM}$. Expression was carried out for $24 \mathrm{~h}$. At the specified time points $(1,2,3,4$, and $24 \mathrm{~h}), 2 \mathrm{ml}$ of culture was harvested by centrifugation (1, $\left.700 \mathrm{~g}, 15 \mathrm{~min}, 4^{\circ} \mathrm{C}\right)$. Bacterial biomass was stored at $-80^{\circ} \mathrm{C}$.

\section{Protein expression analysis}

Proteins were separated under denaturing and reducing conditions in $16.5 \%$ Tricine-sodium dodecyl sulfatepolyacrylamide gel electrophoresis (Tricine-SDS-PAGE) (Schagger and von Jagow 1987), and transferred onto Immobilon-P membrane (0.2- $\mu \mathrm{m}$ pore size; Millipore) at $250 \mathrm{~mA}$ for $10 \mathrm{~h}$ in a buffer containing $25 \mathrm{mM}$ Tris, $0.1 \%$ (w/v) SDS, $192 \mathrm{mM}$ glycine, and $20 \%$ (v/v) methanol pH 8.3 using a Hoeffer apparatus (Amersham Pharmacia). After soaking in $100 \%$ methanol for $30 \mathrm{~s}$, the membrane was dried for $30 \mathrm{~min}$ and then saturated with $1 \%(\mathrm{w} / \mathrm{v}) \mathrm{BSA}$ in $1 \times$ TBST buffer $(150 \mathrm{mM} \mathrm{NaCl}, 10 \mathrm{mM}$ Tris- $\mathrm{HCl} \mathrm{pH} 7.5,0.1 \%$ Tween-20). Then, it was incubated at room temperature for 30 min with an anti-HisTag mouse monoclonal antibody (Merck) diluted 1:1,000 (v/v) in 1× TBST buffer. After three washes with $1 \times$ TBST, the membrane was incubated at room temperature for $30 \mathrm{~min}$ with goat anti-mouse immunoglobulin G (biotinylated) diluted 1:5,000 (v/v) in 1× TBST. The membrane was washed three times with $1 \times$ TBST, then incubated at room temperature for $30 \mathrm{~min}$ with streptavidin peroxidase 
in TBST buffer. The substrate DAB was used to develop color reaction onto the membrane.

Protein minipreps of recombinant divercin AS7 from E. coli under native conditions

Five milliliters of cell pellets resuspended $\left(0.2 \mathrm{~g} \mathrm{ml}^{-1}\right)$ in buffer containing $50 \mathrm{mM} \mathrm{NaH}{ }_{2} \mathrm{PO}_{4} 300 \mathrm{mM} \mathrm{NaCl}$, and $10 \mathrm{mM}$ imidazole, $\mathrm{pH}$ 8.0. The cells were disrupted by sonication in ice-cold water until the required visual viscosity was obtained. The separation of the cytoplasmic soluble fraction from cell debris was performed by centrifugation $(14,000 \mathrm{~g}$, $15 \mathrm{~min}, 4^{\circ} \mathrm{C}$ ). Recombinant divercin AS7 was purified using Ni-NTA agarose beads (Qiagen) according to the manufacturer's recommendations.

\section{Bacteriocin activity assay}

The bacteriocin activity was determined by the agar diffusion test (Richard et al. 2004). Antimicrobial activity of the recombinant divercin AS7 was investigated against L. innocua (ATCC 33090). An overnight culture of L. innocua in LZ broth $\left(37^{\circ} \mathrm{C}\right)$ was diluted in sterile $\mathrm{LZ}$ broth to $10^{6} \mathrm{CFU} \mathrm{ml}^{-1}$ before use. Drops $(20 \mu \mathrm{l})$ of protein suspensions prepared under native conditions were placed on the top of the indicator strain-containing medium. The growth inhibition of indicator strain was determined after $24 \mathrm{~h}$ of incubation at $30{ }^{\circ} \mathrm{C}$ by observing the formation of inhibition zones.

\section{Cell culture}

Human colon adenocarcinoma Caco-2 cells (ECACC, Cat. No. 86010202; Sigma-Aldrich) were grown in a controlled atmosphere of $5 \% \mathrm{CO}_{2}$ at $37{ }^{\circ} \mathrm{C}$ in Dulbecco's modified essential medium (DMEM) containing $4.5 \mathrm{~g} \mathrm{l}^{-1}$ glucose, $2 \mathrm{mM}$ glutamine, $50 \mathrm{\mu g} \mathrm{ml}^{-1}$ gentamycin, $1 \%$ non-essential amino acids, and $10 \%$ heat-inactivated fetal calf serum. Experiments were performed using cells between passages number 49 and 52.

\section{Cytotoxicity assay}

Caco- 2 cells were seeded at a density of $10^{5}$ cells per well in 24-well culture plates (Greiner). Confluent cells were then exposed to divercin AS7 for $24 \mathrm{~h}$. At the end of incubation, the effect of the bacteriocin on the plasma membrane integrity of Caco- 2 cells was estimated by quantification of adenylate kinase release using the ToxiLight Non-destructive Cytotoxicity Bioassay Kit (Lonza). The percentage of cytotoxicity was calculated following the manufacturer's instructions.

\section{Apoptosis assay}

Caco- 2 cells were cultivated in 24-well culture plates and incubated for 8 and $24 \mathrm{~h}$ with divercin AS7. The occurrence of apoptosis was evaluated by the method of DNA laddering (Barry et al. 1990). The supernatant and monolayers were collected and combined into a single sample. Caco- 2 cells were washed with PBS and resuspended in lysis buffer. DNA was isolated using the Genomic Mini DNA purification kit (A\&A Biotechnology) according to the manufacturer's instructions. The DNA samples were separated by electrophoresis at $100 \mathrm{~V}$ for $45 \mathrm{~min}$ in $1 \%(\mathrm{w} / \mathrm{v})$ agarose containing ethidium bromide in $1 \times$ TBE buffer and visualized with UV light.

\section{Epithelial integrity}

The effect of divercin AS7 on intestinal epithelial integrity was assessed by the measurement of transepithelial electrical resistance (TEER) (Klingberg et al. 2005). Caco-2 cells were seeded onto Millicell cell culture inserts (PTFE membrane, $0.4 \mu \mathrm{m}$ pore size; Merck-Millipore, Poland) at $4 \times 10^{5}$ cells $\mathrm{cm}^{-2}$ and cultured for 20 days to obtain a differentiated monolayer with media changes every 2 or 3 days. TEER was measured using a Millicell-ERS volt-ohm meter (Millipore), after $24 \mathrm{~h}$ of incubation of the Caco-2 cells with divercin AS7. The resistance of the monolayer was calculated by subtracting the intrinsic resistance of the system (filter insert alone) from the total resistance (monolayer plus filter insert). The data were displayed as percent TEER relative to the control at time zero.

\section{Results}

Production of recombinant divercin AS7 in E. coli

The expression of divercin fused to His-tag in $E$. coli BL21DE3pLysS/pET-AS7 was induced by the addition of IPTG. Tricine-SDS-PAGE and western blotting analysis confirmed the expression of fusion protein (Fig. 1). The molecular mass of recombinant divercin AS7 containing His-Tag is approximately $8.4 \mathrm{kDa}$ ( $\mathrm{N}$ terminal extension added due to construction requirements led to an enhancement of molecular mass). Maximum of expression occurs after $2 \mathrm{~h}$ postinduction. Analysis of the soluble and insoluble fractions, separated from induced $E$. coli/pET-AS7 cells, revealed that a fraction of the protein forms aggregates in the $E$. coli cell. Bacteriocin activity assay revealed that the soluble fraction of his-tagged divercin AS7 purified on Ni-NTA agarose beads retains its anti-Listeria activity (Fig. 2). 
Fig. 1 Western blot analysis for recombinant bacteriocin AS7 expressed in E. coli/pET-AS7 strain. The cells expressing in SOC medium at $37^{\circ} \mathrm{C}$. Bacterial biomass before IPTGinduction (1) and after IPTGinduction $1 \mathrm{~h} \mathrm{(2)}$ and $2 \mathrm{~h} \mathrm{(3)} \mathrm{were}$ Bands ( 8 kDa) were detected using the anti-HisTag antibody bacteriocin AS7 were cultivated subjected to western blot analysis.
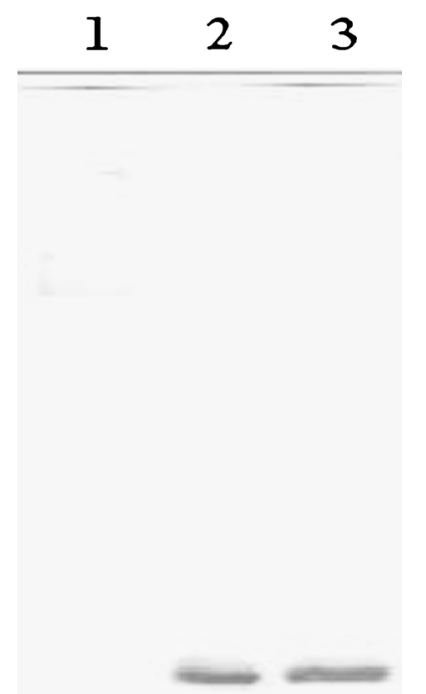

Cytotoxicity assay

The cytotoxicity of divercin AS7 was analyzed on differentiated Caco- 2 cells. For this purpose, the soluble fraction of divercin AS7 was tested at a concentration of $2 \mu \mathrm{g} \mathrm{ml}^{-1}$. The adenylate kinase released by the cells was quantified after $24 \mathrm{~h}$ of incubation. After $24 \mathrm{~h}$ of treatment of Caco- 2 cells with divercin AS7, the percent of cytotoxicity remained at a background level. The observed adenylate kinase release was $2 \%$ for $2 \mu \mathrm{g} \mathrm{ml}^{-1}$ of divercin AS7.

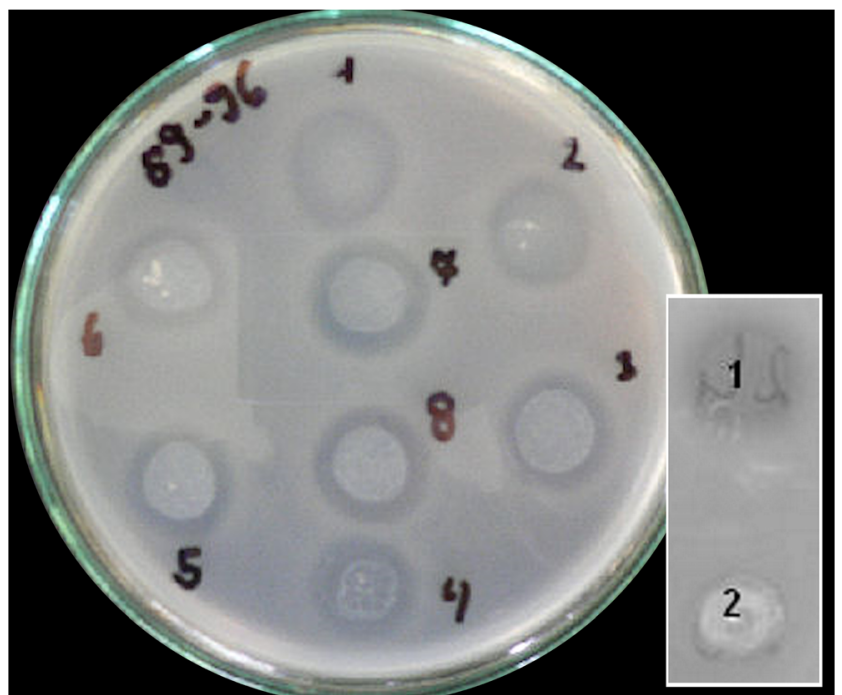

Fig. 2 The agar diffusion test for recombinant bacteriocin AS7. E. coli/ pET-AS7 lysates $(20 \mu \mathrm{l})$ prepared from IPTG-induced culture after $2 \mathrm{~h}$ (1-8) were plated on LZ agar inoculated with Listeria innocua indicator strain and incubated overnight at $30^{\circ} \mathrm{C}$. Growth inhibition zones indicate action of recombinant bacteriocin AS7. The inset shows positive control ( 1 diluted native bacteriocin AS7) and E. coli/pET-28b+ lysate ( 2 negative control)
Apoptosis assay

DNA fragmentation is a common hallmark of apoptotic cells (Barry et al. 1990). DNA fragmentation assay was used to determine whether Caco-2 cells undergo apoptosis after incubation with divercin AS7. The quality of DNA isolated from Caco- 2 cells after $24 \mathrm{~h}$ of treatment with $2 \mu \mathrm{g} \mathrm{ml}^{-1}$ of divercin AS7 was similar to DNA isolated from untreated cells (Fig. 3). No fragmentation (apoptotic ladder) was seen on the agarose gel, indicating that the divercin AS7 does not induce apoptosis of human intestinal enterocytes.

\section{Epithelial integrity}

The effect of divercin AS7 on the epithelial monolayer integrity was studied on differentiated Caco- 2 cells by measuring the transepithelial electrical resistance (TEER). After $24 \mathrm{~h}$ of treatment with divercin AS7 at $2 \mu \mathrm{g} \mathrm{ml}^{-1}$, no significant reduction in the TEER was observed. The average value of the TEER was $98.6 \%$ of the initial level.

\section{Discussion}

Bacteriocins have the potential for use as novel antibiotics and, in combination with traditional methods, as food preserving agents. To develop bacteriocins for these applications such

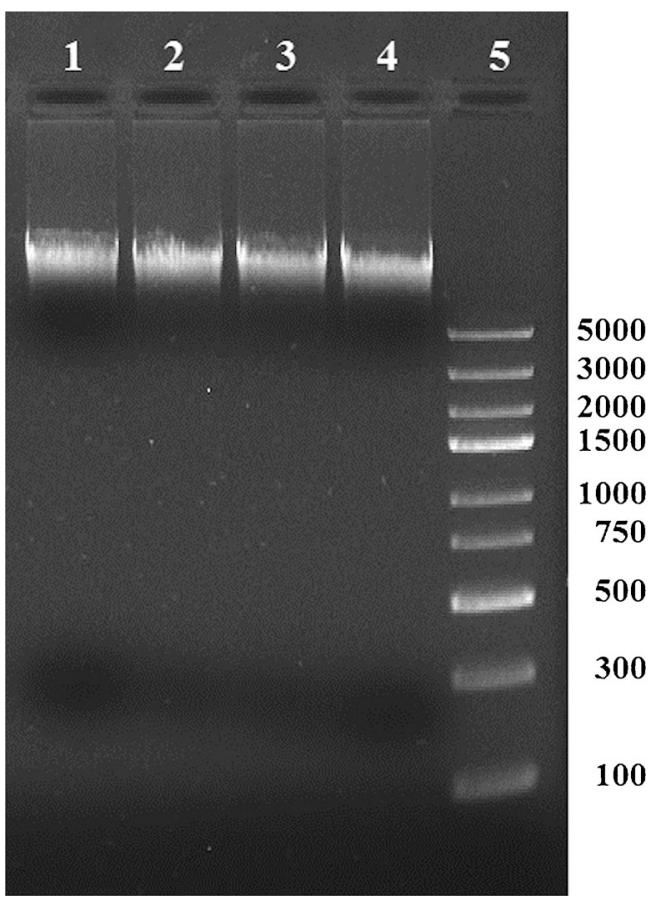

Fig. 3 Agarose gel electrophoresis for DNA fragmentation assay (apoptotic ladder) showing Caco-2 genomic DNA isolated from untreated cells (lane 1 negative control) and cells treated with bacteriocin AS7 for $1 \mathrm{~h}$ (lane 2), $4 \mathrm{~h}$ (lane 3) and $24 \mathrm{~h}$ (lane 4). Lane 5 DNA ladder 
as are needed for structural and functional studies, it is necessary to produce active highly purified peptide. Generally, class IIa bacteriocins have been obtained through the growth of the natural producer and peptide purification using cation exchange and reverse phase chromatography (Berjeaud and Cenatiempo 2004) or by phase partioning (Metivier et al. 2000). Heterologous expression of peptides is an alternative with many advantages, e.g., controlled expression, ease of purification, production of recombinant bacteriocin with a fusion tag, or expression of truncated forms for further analysis. Heterologous expression of class IIa bacteriocins in $E$. coli has shown that recombinant bacteriocins can be produced in an active form (Ingham et al. 2005; Richard et al. 2004; Yildirim et al. 2007). Although some problems have been reported with sub-cloned native genes of bacteriocins (Richard et al. 2004), we decided to express divercin AS7 from a native gene cloned in commercially available plasmid vector $\mathrm{pET} 28 \mathrm{~b}+$. In our study, we obtained active recombinant divercin AS7 as a fusion protein with His-Tag. Recombinant divercin AS7 maintains its antibacterial activity as demonstrated by the agar diffusion test using L. innocua as the indicator strain. The activity of homologs of this bacteriocin have been linked to the C-terminus and its membranepenetrating function, therefore the tag in our recombinant protein is fused to the N-terminus of peptide. Plasmid stability was monitored at every step of the experiment (data not shown), confirming that our recombinant construct is stable consisting of an insert. Due the small size of bacteriocins, they are not easily visualized on polyacrylamide gels, therefore we used Tricine gel electrophoresis and commercially available antibodies to the fusion partner (His-Tag) to identify production of the fusion bacteriocin. We observed formation of insoluble aggregates of divercin AS7 in the $E$. coli cell, but the use of a lower concentration of induction factor $(0.1 \mathrm{mM}$ IPTG) enabled us to obtain a soluble fraction of the correctly folded peptide. Further study will be required to determine the relationship between IPTG concentration and the efficiency of active protein synthesis. Production of divercin AS7 using a heterologous host could be limited by the higher cost compared to the natural way, but the protein obtained could be highly purified and used for in vitro studies on human cells. Our studies on the bacteriocin divercin AS7's influence on intestinal epithelial integrity and cytotoxicity have shown that, at the concentration used $\left(2 \mu \mathrm{g} \mathrm{ml}^{-1}\right)$, the recombinant protein is not cytotoxic to undifferentiated Caco-2 cells. Moreover, we have shown on differentiated Caco-2 cells that divercin AS7 did not change the permeability of reconstructed epithelium. No variation in TERR was observed between the control value and the TERR of divercin AS7-treated Caco-2 cells. In studies on bacteriocin plantaricin $\mathrm{A}$, it was shown that this has the potential to protect the function of the human intestinal barrier (TERR increase). Plantaricin A also enlarged the Caco-2 cell viability and contributed to the prevention of cell damage (Di
Cagno et al. 2010). In our study, the absence of an apoptotic effect in the DNA fragmentation assay, along with lack of cytotoxicity and no damage to cell permeability, allow us to conclude that recombinant divercin AS7 at the concentration tested is not toxic to enterocytes and is a promising peptide for the food and pharmaceutical industry.

Acknowledgments The authors would like to thank Prof. Jeff Cole (School of Biosciences, University of Birmingham, UK) for helpful comments on the induction of protein expression in a heterologous system. This work was supported by a grant from the Ministry of Science and Higher education no. NN312323935 in years 2008-2011.

Open Access This article is distributed under the terms of the Creative Commons Attribution License which permits any use, distribution, and reproduction in any medium, provided the original author(s) and the source are credited.

\section{References}

Abee T, Krockel L, Hill C (1995) Bacteriocins: modes of action and potentials in food preservation and control of food poisoning. Int $\mathrm{J}$ Food Microbiol 28:169-185

Barry MA, Behnke CA, Eastman A (1990) Activation of programmed cell death (apoptosis) by cisplatin, other anticancer drugs, toxins and hyperthermia. Biochem Pharmacol 40:2353-2362

Berjeaud JM, Cenatiempo Y (2004) Purification of antilisterial bacteriocins. Methods Mol Biol 268:225-233

De Man JC, Rogosa M, Sharpe E (1960) A medium for the cultivation of lactobacilli. J Appl Microbiol 23:130-135

Di Cagno R, De Angelis M, Calasso M, Vincentini O, Vernocchi P, Ndagijimana M, De Vincenzi M, Dessi MR, Guerzoni ME, Gobbetti M (2010) Quorum sensing in sourdough Lactobacillus plantarum DC400: induction of plantaricin A $(\mathrm{P} \ln \mathrm{A})$ under co-cultivation with other lactic acid bacteria and effect of PlnA on bacterial and Caco-2 cells. Proteomics 10: $2175-2190$

Ingham AB, Sproat KW, Tizard ML, Moore RJ (2005) A versatile system for the expression of nonmodified bacteriocins in Escherichia coli. $\mathrm{J}$ Appl Microbiol 98:676-683

Jozefiak D, Sip A, Rawski M, Rutkowski A, Kaczmarek S, Hojberg O, Jensen BB, Engberg RM (2011) Dietary divercin modifies gastrointestinal microbiota and improves growth performance in broiler chickens. Br Poult Sci 52:492-499

Klaenhammer TR (1993) Genetics of bacteriocins produced by lactic acid bacteria. FEMS Microbiol Rev 12:39-85

Klingberg TD, Pedersen MH, Cencic A, Budde BB (2005) Application of measurements of transepithelial electrical resistance of intestinal epithelial cell monolayers to evaluate probiotic activity. Appl Environ Microbiol 71:7528-7530

Lebois M, Connil N, Onno B, Prevost H, Dousset X (2004) Effects of divercin $\mathrm{V} 41$ combined to $\mathrm{NaCl}$ content, phenol (liquid smoke) concentration and $\mathrm{pH}$ on Listeria monocytogenes Scott A growth in BHI broth by an experimental design approach. J Appl Microbiol 96:931-937

Maher S, McClean S (2006) Investigation of the cytotoxicity of eukaryotic and prokaryotic antimicrobial peptides in intestinal epithelial cells in vitro. Biochem Pharmacol 71:1289-1298

Metivier A, Pilet MF, Dousset X, Sorokine O, Anglade P, Zagorec M, Piard JC, Marion D, Cenatiempo Y, Fremaux C (1998) Divercin 
V41, a new bacteriocin with two disulphide bonds produced by Carnobacterium divergens V41: primary structure and genomic organization. Microbiology 144:2837-2844

Metivier A, Boyaval P, Duffes F, Dousset X, Compoint JP, Marion D (2000) Triton X-114 phase partitioning for the isolation of a pediocin-like bacteriocin from Carnobacterium divergens. Lett Appl Microbiol 30:42-46

Murinda SE, Rashid KA, Roberts RF (2003) In vitro assessment of the cytotoxicity of nisin, pediocin, and selected colicins on simian virus 40-transfected human colon and Vero monkey kidney cells with trypan blue staining viability assays. J Food Prot 66:847853

Nes IF, Diep DB, Håvarstein LS, Brurberg MB, Eijsink V, Holo H (1996) Biosynthesis of bacteriocins in lactic acid bacteria. Antonie Van Leeuwenhoek 70:113-128

Parisien A, Allain B, Zhang J, Mandeville R, Lan CQ (2008) Novel alternatives to antibiotics: bacteriophages, bacterial cell wall hydrolases, and antimicrobial peptides. J Appl Microbiol 104:1-13

Richard C, Brillet A, Pilet MF, Prevost H, Drider D (2003) Evidence on inhibition of Listeria monocytogenes by divercin V41 action. Lett Appl Microbiol 36:288-292
Richard C, Drider D, Elmorjani K, Marion D, Prévost H (2004) Heterologous expression and purification of active divercin V41, a class IIa bacteriocin encoded by a synthetic gene in Escherichia coli. J Bacteriol 186:4276-4284

Sambrook J, Fritsch EF, Maniatis T (1989) Molecular cloning: a laboratory manual, 2nd edn. Cold Spring Harbor Laboratory Press, Cold Spring Harbor

Schagger H, von Jagow G (1987) Tricine-sodium dodecyl sulfatepolyacrylamide gel electrophoresis for the separation of proteins in the range from 1 to $100 \mathrm{kDa}$. Anal Biochem 166:368-379

Sip A, Grajek W, Boyaval P (1998) Enhancement of bacteriocin production by Carnobacterium divergens AS7 in the presence of a bacteriocin-sensitive strain Carnobacterium piscicola. Int J Food Microbiol 42:63-69

Todorov SD, Wachsman M, Tome E, Dousset X, Destro MT, Dicks LM, Franco BD, Vaz-Velho M, Drider D (2010) Characterization of an antiviral pediocin-like bacteriocin produced by Enterococcus faecium. Food Microbiol 27:869-879

Yildirim S, Konrad D, Calvez S, Drider D, Prévost H, Lacroix C (2007) Production of recombinant bacteriocin divercin V41 by high cell density Escherichia coli batch and fed-batch cultures. Appl Microbiol Biotechnol 77:525-531 